\title{
PRODUÇÃO E REPRODUÇÃO: MODO DE VIDA CAMPONÊS ATRAVẼS DA MELIPONICULTURA NO MÉDIO AMAZONAS, ITAPIRANGA-AM.
}

\author{
Kleten Kelle Lima de Oliveira \\ Mestranda do Programa de Pós-graduação em Geografia - UFAM \\ Universidade Federal do Amazonas \\ kleten.oliveira@gmail.com \\ Manuel de Jesus Masulo da Cruz \\ Professor Doutor do Programa de Pós-graduação em Geografia - UFAM \\ Universidade Federal do Amazonas \\ masulo@bol.com.br
}

RESUMO: A presente pesquisa em andamento tem como propósito compreender as formas de produção e reprodução do modo de vida em que se encontra o camponês-ribeirinho, no qual utiliza estratégias de permanência no campo, dentre o qual pratica a atividade da meliponicultura (criação de abelhas indígenas sem ferrão), a área de abrangência dos estudos se localiza no município de Itapiranga/AM, em comunidades de terra firme e várzea estão presentes com suas formas de organização da produção camponesa no ambiente amazônico.

Palavras-chave: camponês-ribeirinho, meliponicultura, Amazonas/BR.

\section{INTRODUÇÃO}

A pesquisa se fundamenta em variadas bases da literatura, levando em consideração o seu cunho teórico e prático, buscando essencialmente os meios que sustente a compreensão da problemática proposta a ser trabalhada e a realização dos objetivos da pesquisa. A pesquisa será norteada a partir de quatro principais conceitos: camponês, lugar, territorialidade e meliponicultura.

Para Cavalcante et.al. (2009), A atual configuração das políticas agrícolas na Amazônia, ainda segue um modelo não adaptado às condições ambientais da região. Este aspecto é determinante para a permanência do homem no campo. O elevado nível de burocracia estabelecida na busca pelo acesso ao crédito e regularização fundiária, além da baixa capacidade dos sistemas de assistência técnica dificulta o desenvolvimento socioeconômico das comunidades tradicionais amazônicas. Faz-se necessário o estabelecimento de tecnologias que levem em consideração o potencial ambiental e de biodiversidade local, com impacto ambiental mínimo, baixo custo de implantação e acessibilidade ao mercado, esses fatores podem determinar a permanência do homem no campo. Mas o saber da técnica que o camponês carrega consigo e no seu seio familiar faz com que prossiga na continuidade a sua reprodução aplicando assim novas estratégias de estabilidade no campo e desenvolvendo autonomia sobre as práticas mais diversas de suas atividades para o sustento familiar e o suprimento de suas necessidades, pois a meliponicultura auxilia no incremento da 
PRODUÇÃO E REPRODUÇÃO: MODO DE VIDA CAMPONÊS ATRAVÉS DA MELIPONICULTURA NO MÉDIO AMAZONAS, ITAPIRANGA-AM.

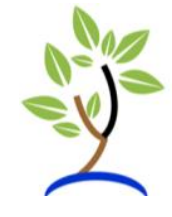

renda familiar e conservam essas abelhas para o equilíbrio do Ecossistema Amazônico.

Portanto está pesquisa trata da formação de um campesinato na $8^{\mathbf{a}}$ sub-região do Médio Amazonas, mais especificamente no município de Itapiranga-AM. O setor primário da economia (agricultura, pecuária, agropecuária, extrativismo e caça) é o principal responsável na geração de renda do município e emprega a grande parte do contingente populacional.

\section{MATERIAIS E MÉTODOS}

A pesquisa é de caráter exploratório, pautando-se em uma abordagem qualitativa e quantitativa.

1ㅡㅡ Fase - Revisão Bibliográfica: anterior às práticas de campo foram realizados levantamento bibliográfico de autores e obras da ciência geográfica que tratam da teoria e conceitos pertinentes ao objeto de análise dessa pesquisa. Os principais conceitos trabalhados serão os de camponês, lugar, territorialidade e meliponicultura. Juntamente com a revisão da literatura regional para a identificação de obras que abordam sobre o tema dos objetos desta pesquisa, assim como de áreas correlatas que agreguem valor e sentido teórico a esta linha de abordagem amazônica.

$2^{\text {a }}$ Fase - Prática de Campo na área de estudo do município de Itapiranga-AM, nas áreas urbana e rural, tendo assim como recorte geográfico as Comunidades Rurais de Paraguai, Santa Maria do Madrubá, São José da Enseada, Ilha Grande, Terra Nova e na sede da cidade, por se tratarem da espacialidade e territorialidades produzidas segundo Cruz (2007) pelo camponês-ribeirinho, em que pratica a atividade de meliponicultura.

Já foram realizadas entrevistas semiestruturadas a partir da aplicação de questionários abertos com as famílias produtoras de mel da região do Médio Amazonas, município de Itapiranga-AM, nas Comunidades Rurais de Paraguai, Santa Maria do Madrubá, São José da Enseada, Ilha Grande, Terra Nova e na sede da cidade, para explorar as informações relacionadas a produção dos meios materiais para reprodução camponesa, as técnicas de produção, espécies utilizadas, o conhecimento da ecologia local, organização sócio espacial e relações mercantis para a compreensão acerca da economia gerada com a comercialização do mel de abelhas sem ferrão. Dessa forma, para se compreender em quais circunstâncias foram iniciadas as atividades de meliponicultura pelas comunidades rurais do município, várias movimentações camponesas se mobilizaram através de entidades e dos organismos governamentais localizados na sede municipal, que será à base de sustentação desta pesquisa.

No entanto, pelo conhecimento da área de pesquisa e algumas práticas de campo, foi constatado raras literaturas sobre o município de Itapiranga (tanto no campo quanto na cidade), desse modo, recorrerá às vozes orais dos moradores mais antigos, tanto em comunidades rurais e na cidade. Na primeira etapa da pesquisa, não foi 
PRODUÇÃO E REPRODUÇÃO: MODO DE VIDA CAMPONÊS ATRAVÉS DA MELIPONICULTURA NO MÉDIO AMAZONAS, ITAPIRANGA-AM.

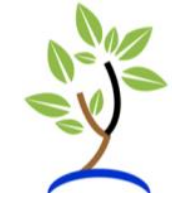

determinada faixa etária especifica para o questionário ou conversas informais, pois se considera que todos os moradores do município que podem voluntariamente contribuir com esta pesquisa, pois são detentores de conhecimentos empíricos sobre o local estudado, levando em consideração suas experiências de vida e observações. Por meio de seus relatos desvendam as entranhas que ligam esses camponesesribeirinhos ao passado recente, para assim compreender as atividades econômicas que predominam nas várzeas e terra firme e impulsionam a visibilidade do município, desde as relações estabelecidas com o mercado, suas praticas sociais, culturais e políticas, as formas de organização que fortalecem a luta camponesa, a inserção da atividade de meliponicultura nas unidades familiares entre outros fatores que acontecem no seio das relações capitalistas aos quais participam.

Encontra-se em andamento as etapas seguintes da pesquisa, com a realização de levantamentos de dados primários e secundários, entrevistas orais, anotações de campo, aplicação de questionários, registro fotográfico, confecção de mapas cartográficos, acompanhamento sistemático em determinado período do ano da atividade e da produção camponesa, bem como nos eventos culturais (festas, torneios, brincadeiras, etc.). Assim, se fará uma pesquisa de cunho participante, que segundo Severino (2007) se caracteriza pela necessidade do pesquisador ao ter que realizar a observação dos fenômenos, compartilhar da vivencia dos sujeitos pesquisados, interagindo de forma sistemática e permanente, ao longo da pesquisa.

\section{RESULTADOS E DISCUSSÃO}

$\mathrm{Na}$ prática de campo realizada no mês de fevereiro de 2018 no município de Itapiranga/AM, foram colhidos resultados parciais e primários da área e comunidades estudadas. Os camponeses-ribeirinhos são produtores que fazem parte da Associação de Promotores da Atividade de Meliponicultura do Estado do Amazonas, que é uma iniciativa do Instituto Iraquara, cujo objetivo é a geração de trabalho, renda e preservação ambiental, em que promove programas integrados no manejo de criação de abelhas indígenas sem ferrão, nos quais as espécies são Melipona seminigra merrilae (jandaíra) e Melipona compressipes manaosensis (jupará). O financiamento para a manutenção das atividades junto às comunidades advém principalmente de Fundos Sociais de acordo com a Lei nํㅜ 11.326 de 2006.

De acordo com Bustamante et. al. (2016), a importância em se criar às abelhas indígenas sem ferrão envolve três aspectos: o ambiental, o econômico e o socioeducativo, assim como Sistemas Agloflorestais conforme SILVA (2017). De acordo com a tabela 01, cerca de quarenta famílias camponesas-ribeirinhas praticam a atividade de meliponicultura no município de Itapiranga/AM, distribuídas assim na área de terra firme a na várzea. 
PRODUÇÃO E REPRODUÇÃO: MODO DE VIDA CAMPONÊS ATRAVÉS DA MELIPONICULTURA NO MÉDIO AMAZONAS, ITAPIRANGA-AM.

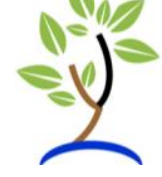

Tabela 01: Quantitativo de Comunidades e Produtores da Associação de Promotores da Atividade de Meliponicultura do Estado do Amazonas.

\begin{tabular}{lclc}
\hline \multicolumn{1}{c}{ Terra Firme } & $\begin{array}{l}\text { Quantidade } \\
\text { Produtores }\end{array}$ & \multicolumn{1}{c}{ Várzea } & $\begin{array}{l}\text { Quantidade } \\
\text { Produtores }\end{array}$ \\
\hline $\begin{array}{l}\text { Comunidade São } \\
\text { José da Enseada }\end{array}$ & 10 & $\begin{array}{l}\text { Comunidade } \\
\text { Paraguai }\end{array}$ & 10 \\
$\begin{array}{l}\text { Santa Maria do } \\
\text { Madrubá }\end{array}$ & 05 & $\begin{array}{l}\text { Comunidade Ilha } \\
\text { Grande }\end{array}$ & 03 \\
\hline $\begin{array}{l}\text { Terra Nova } \\
\text { Sede Itapiranga }\end{array}$ & 05 & & - \\
\hline Sub-Total & 07 & Sub-Total & 13 \\
\hline Total = 40 famílias & 27 & Fonte: Instituto Iraquara. Org: Kleten Lima, 2018.
\end{tabular}

\section{REFERÊNCIAS}

BUSTAMANTE, N. C. R. COSTA, K. B. LOPES, M. C. A Meliponicultura na Região Amazônica: instrumento de sustentabilidade para o pequeno produtor. Manaus: Edua, 2016.

CAVALCANTE, D. G.; MATOS, L. L.; PINHEIRO, E. S._A Meliponicultura como Fator de Permanência do Homem no Campo. In: XIX Encontro Nacional de Geografia Agrária: Formação e contemporaneidade da diversidade sócio-espacial no campo. São Paulo: Laboratório de Geografia Agrária - DG/FFLHC-USP, 2009. p. 1-12.

CRUZ, M. J. M. Territorialização camponesa na várzea da Amazônia. 274 p. (Tese de doutorado. Doutorado em Geografia Humana da Universidade de São Paulo). São Paulo: USP, 2007.

SEVERINO, A. J. Metodologia do trabalho científico. - São Paulo: Cortez, 2007.

SILVA, F. A. M.; GEMIM, B. S. Meliponicultura em sistemas agroflorestais: alternativa de renda, diversificação agrícola e serviços ecossistêmicos. Revista Agro@mbiente On-line, v. 11, p. 361, 2017. 